\title{
Linfoma T subcutâneo do tipo paniculite: relato de um caso acometendo paciente pediátrico
}

\author{
Subcutaneous panniculitic $T$ cell lymphoma: a case report affecting a child
}

\begin{abstract}
Lúcia de Noronha $^{1}$
Fabiola Medeiros $^{2}$
Luciano Monte Serrat Prevedello
Vanessa Dello Monaco Martins
Flora Watanabe
José Fillus Neto
unitermos resumo

Linfoma T subcutâneo

Paniculite

Criança

Os autores relatam um caso de linfoma T subcutâneo do tipo paniculite em uma paciente feminina de 3 anos, apresentando havia um mês múltiplos nódulos subcutâneos, indolores, disseminados no abdome, região peitoral e cervical. Ao exame histopatológico, evidenciou-se um linfoma T infiltrando tecido adiposo subcutâneo. Os linfomas T subcutâneos representam uma entidade clinicopatológica distinta, sendo raro o acometimento pediátrico.

Lúcia de Noronha ${ }^{1}$ José Fillus Neto ${ }^{4}$
\end{abstract}

\section{abstract}

We report a case of lypotrophic lymphoma affecting a 3-year-old child with 1-month history of nontender subcutaneous nodules disseminated throughout the abdomen, chest and cervical region. Histological examination showed a T-cell lymphoma affecting the subcutaneous tissue. Subcutaneous panniculitis-like T-cell lymphoma is an unusual cutaneous T-cell lymphoma that rarely affects pediatric patients. key words

T-cell lymphoma

Panniculitis

Child

\section{Introdução}

Os linfomas cutâneos (micose fungóide e síndrome de Sézary), cujo curso clínico é freqüentemente indolente e de sobrevida prolongada, representam, aproximadamente, a metade dos linfomas não-Hodgkin de células T periféricas (LTP). $\mathrm{O}$ restante dos casos apresenta-se de maneira muito mais agressiva (1). Recentemente, foi descrita uma nova categoria de LTP, de ocorrência rara, cujo acometimento primário se faz em tecido subcutâneo. A entidade, denominada linfoma T subcutâneo do tipo paniculite (LTSCP), acomete preferencialmente muIheres de meia-idade, sendo caracterizada clinicamen- te por múltiplos nódulos subcutâneos ou placas distribuídos em tronco ou extremidades, febre, astenia e perda ponderal. A fase mais agressiva da enfermidade é representada pela síndrome hemofagocítica, a qual se manifesta, entre outras apresentações, com pancitopenia e presença de eritrofagocitose em fígado, baço, linfonodos e medula óssea $(1,3,13,19)$. Histologicamente, a lesão caracteriza-se pelo comprometimento primário do tecido celular subcutâneo, com distribuição das células neoplásicas nos septos interlobulares, associado a necrose adiposa, à semeIhança de uma paniculite septal.
1. Médica patologista da Unidade de Patologia Pediátrica e Perinatal (UPP), Serviço de Anatomia Patológica do Hospital de Clínicas (SAP-HC), UFPR; mestre em Patologia.

2. Acadêmico de Medicina; estagiário da UPP, SAP-HC, UFPR. 3. Médica pediatra do Hospital Infantil Pequeno Príncipe, Curitiba. 4. Médico dermatopatologista SAP-HC, UFPR. 


\section{Relato do caso}

L.N.C.C., sexo feminino, 3 anos de idade, foi atendida no ambulatório de hematologia do Hospital Infantil Pequeno Príncipe, em Curitiba (PR), apresentando vários nódulos subcutâneos hiperemiados, com um mês de evolução. Relatava febre baixa não-aferida e emagrecimento de $1 \mathrm{~kg}$ neste período.

Ao exame físico, apresentava-se em bom estado geral, afebril, com leve palidez cutânea, pesando $17 \mathrm{~kg}$. Mostrava formações nodulares subcutâneas endurecidas, indolores, hiperemiadas, com algumas áreas de descamação. As lesões localizavam-se no abdome e nas regiões peitoral esquerda, cervical, supraclavicular e supra-orbitária direita, com tamanho variando de $1 \mathrm{~cm}$ a $4 \mathrm{~cm}$. Não foram observadas visceromegalia ou adenomegalia. Os exames laboratoriais incluíram hemograma completo e provas de função hepática, todos sem alterações. Realizou-se uma biópsia do nódulo, na qual observou-se infiltrado de linfócitos atípicos de núcleos convolutos, permeando o tecido celular subcutâneo, associado a histiócitos, fagocitando

\section{8}

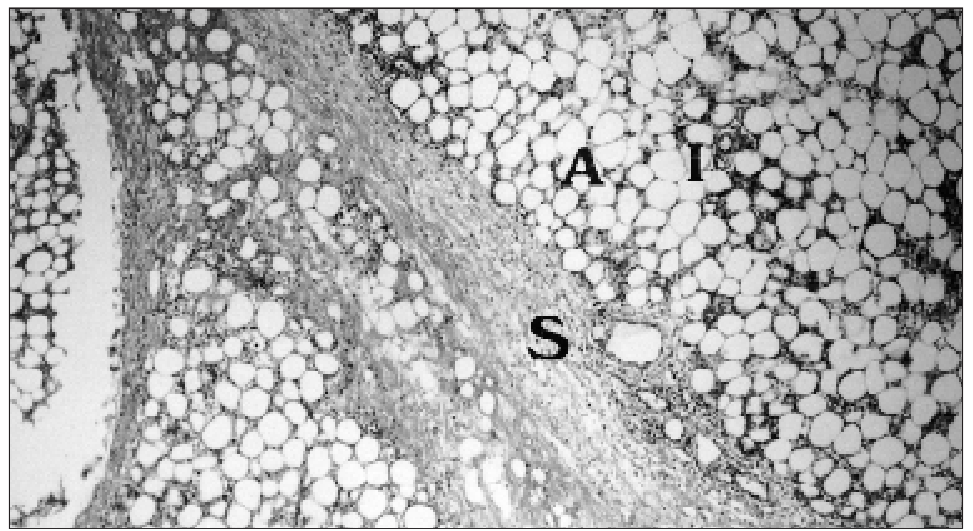

Figura 1A - Infiltrado celular (I) no tecido adiposo subcutâneo (A), predominantemente lobular, poupando os septos (S), à semelhança de uma paniculite lobular (hematoxilina-eosina, 100x)

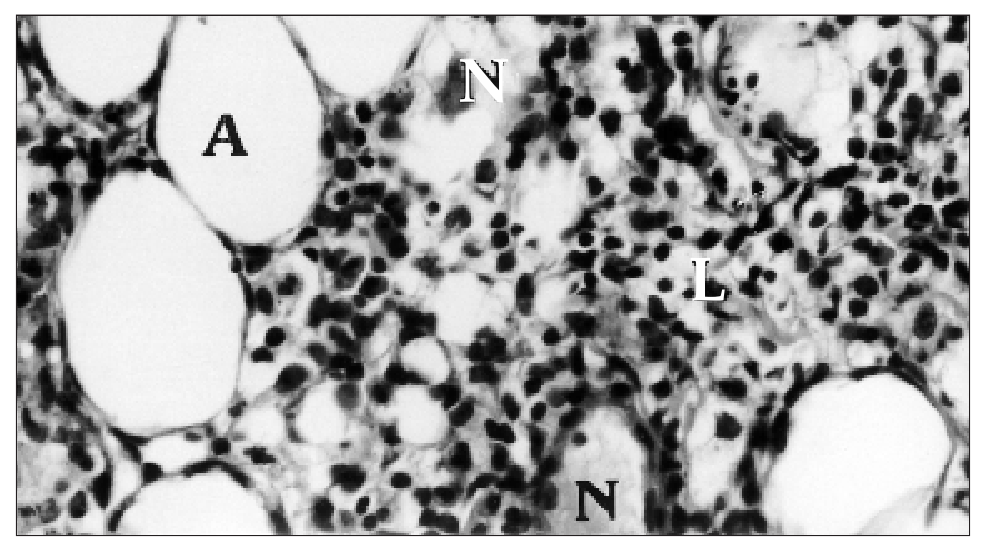

Figura 1B - Detalhe da micrografia anterior, mostrando inúmeros linfócitos atípicos $(L)$ envolvendo adipócitos (A). Há ainda áreas de necrose gordurosa (N) (hematoxilina-eosina, 400x) hemácias e linfócitos pequenos (Figuras 1 e 2). Foi realizado um estudo imunoistoquímico em material embebido em parafina. O painel de anticorpos utilizados incluiu L26 (CD20), LCA (PD7/26/16 e 2B11), UHCL-1 (CD45R0), Ber-H2 (CD30), KP1 (CD68), sendo todos da Dako Corporation, Carpenteria, Califórnia. A neoplasia revelou positividade para LCA e UCHL-1, evidenciando tratar-se de neoplasia de linhagem linfocitária com fenotipagem T. Os histiócitos maduros mostraram positividade para CD68. A pesquisa para CD20 foi negativa. Desta forma, estabeleceu-se o diagnóstico de linfoma subcutâneo de células T associado à presença de histiócitos em emperipolese (Figuras 1 e 2).

Foram realizadas biópsia de medula óssea e punção do liquor para estadiamento da doença, as quais demonstraram celularidade habitual e ausência de infiltração neoplásica ou sinais de hemofagocitose.

\section{Discussão}

Os linfomas freqüentemente acometem a pele, especialmente a derme e a epiderme, podendo-se estender secundariamente para o tecido celular subcutâneo, como ocorre na micose fungóide e na síndrome de Sézary. Raramente os linfomas apresentam-se com o envolvimento primário do tecido celular subcutâneo, sem comprometer a derme e a epiderme, na ausência de doença nodal ou generalizada (13). Entre os tipos de linfomas que envolvem primariamente o tecido celular subcutâneo incluem-se os linfomas subcutâneos do tipo paniculite, anaplásicos de grandes células e angiocêntricos, em todos predominando as células da linhagem T. Assim, a designação linfoma T subcutâneo abrange diferentes tipos de linfomas de células T, com fenotipagem semelhante, porém clínica e morfologicamente diferentes (13).

O linfoma T subcutâneo do tipo paniculite (LTSCP) foi inicialmente descrito como um subtipo de linfoma T pós-tímico envolvendo o tecido celular subcutâneo. Corresponde a um linfoma de células T periférico caracterizado pelo comprometimento primário do tecido celular subcutâneo. Apresenta células neoplásicas distribuídas nos septos interlobulares, associadas a necrose adiposa, à semelhança de uma paniculite septal $(2,4,8,14,17)$. Alguns autores acreditam que relatos anteriores de histiocitoses cutâneas malignas e paniculites histiocíticas citofágicas correspondam a $\operatorname{LTSCP}(8,12,13)$. Existem vários subtipos de linfomas 
T subcutâneos do tipo paniculite. Os linfomas T angiocêntricos carcterizam-se por um arranjo perivascular com necrose fibrinóide da parede do vaso. Clinicamente observam-se nódulos e ulcerações na pele, sendo freqüente o envolvimento extracutâneo $(5,18)$. Os linfomas de células natural killlers constituem-se de células grandes e atípicas associadas a necrose gordurosa do tecido celular subcutâneo. São CD3 e CD8positivos, com imunorreatividade para antígenos CD56 e CD57 associados a natural killer (7, 20). O caso aqui descrito corresponde a um linfoma de células pequenas associadas e histiócitos maduros em emperipolese, com necrose do tecido celular subcutâneo, configurando um linfoma $T$ subcutâneo do tipo paniculite (LTSCP).

Cerca de 45 casos de LTSCP já foram descritos (13). $\mathrm{O}$ estudo destes casos demonstrou que, ao contrário dos linfomas epidermotrópicos, o LTSCP é mais freqüente no sexo feminino, numa relação de 1,4:1 (17). A idade dos pacientes é variável. Em um estudo de 44 casos de LTSCP, von den Driesch et al. encontraram uma idade média de 45,4 anos, variando entre 10 e 82 anos (13). Os LTSCP são raros em crianças $(9,14)$. Em 1994, surgiu o primeiro relato de LTSCP em crianças, acometendo uma menina de 11 e um menino de 10 anos (14). Hung et al. descreveram um LTSCP associado a mielofibrose idiopática em uma menina de 5 anos (9). O caso em discussão é o de uma menina de 3 anos de idade.

A clínica é inespecífica e indica um possível quadro neoplásico cursando com perda de peso, febre, calafrios, fadiga, icterícia e mialgias (13). Pode-se encontrar hepatoesplenomegalia, mas a linfadenopatia raramente é encontrada no $\operatorname{LTSCP}(13,18)$. No caso aqui relatado, a paciente apresentava, no início, história de um quadro febril e perda de peso, não havendo visceromegalias ou adenomegalias evidenciáveis ao exame físico.

O local do envolvimento cutâneo varia, havendo maior acometimento das extremidades e do tronco. Podem ocorrer, ainda, em face, pescoço, tornozelo, axila, virilha e nádegas. As lesões cutâneas apresentam-se como múltiplos nódulos firmes ou placas, de coloração parda a avermelhada, variando de $0,5 \mathrm{~cm}$ a $13 \mathrm{~cm}$ de diâmetro (18). No presente relato, a paciente mostrava formações nodulares de características semelhantes às relatadas na literatura, localizadas principalmente no tronco.

O diagnóstico baseia-se nos achados histopatológicos, confirmados com estudo imunoisto-

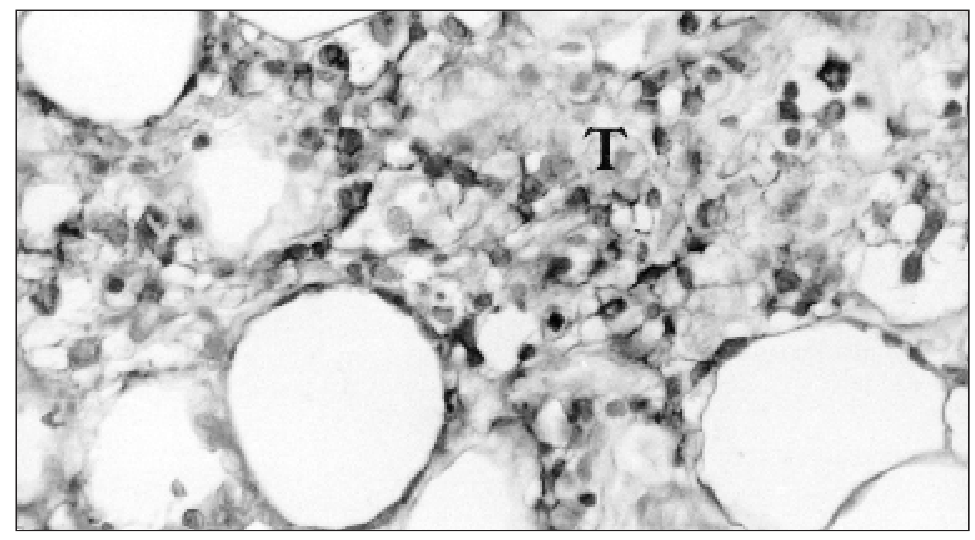

Figura 2A - Imunoistoquímica para LCA e UCHL-1 mostrando linfócitos atípicos neoplásicos positivos

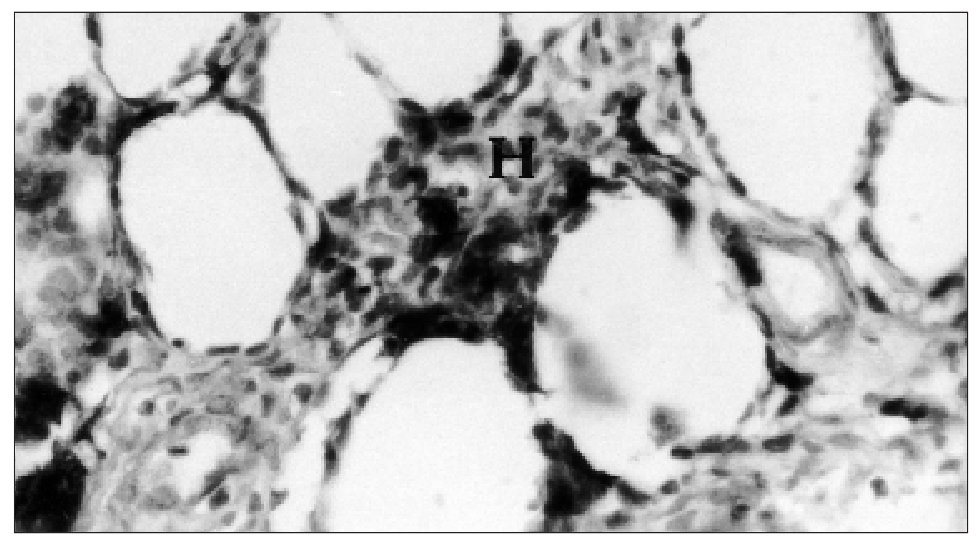

Figura 2B - Imunoistoquímica para CD68 mostrando histiócitos (H) positivos (400x)

químico. O infiltrado celular no LTSCP localiza-se no tecido subcutâneo, envolvendo, principalmente, os septos interlobulares e, secundariamente, os lóbulos, podendo associar-se a grandes áreas de necrose gordurosa. As células geralmente não apresentam angiotropismo e raramente infiltram anexos cutâneos. Os linfócitos T neoplásicos variam pouco de tamanho, sendo geralmente pequenos, com núcleos cerebróides e citoplasma escasso. As células neoplásicas freqüentemente acompanhamse de uma população de histiócitos maduros em emperipolese.

Muitos autores têm demonstrado, através de técnicas imunoistoquímicas, que o linfoma subcutâneo do tipo paniculite pertence à linhagem T. As células neoplásicas expressam CD45 (antígeno leucocitário), mas também tem sido relatado que expressam CD2, entre outros marcadores de células T. As células T não expressam CD68, cuja positividade limita-se aos macrófagos. Normalmente não há expressão de antígenos associados à linhagem B. Entretanto já foram descritos alguns casos onde houve expressão concomitante de fenótipo de células $B(5,10,12,17,18)$. 
Estudos recentes sugerem uma origem linfocitária citotóxica para o $\operatorname{LTSCP}(7,10)$. Os linfócitos T citotóxicos contêm grânulos azurófilos constituídos por proteínas específicas, principalmente perforin, granzimas A e B e TIA-1. Foi demonstrada positividade para TIA-1 e perforin nos 16 casos estudados, fornecendo evidências de que estes tumores derivam da ativação de linfócitos T citotóxicos (10). A presença de antígenos associados a céulas natural killers como CD56 e CD57 também suporta esta hipótese (7). Os anticorpos para a determinação da presença destes antígenos não foram testados no presente caso.

A associação do LTSCP com o vírus Epstein-Barr é controversa. A maioria dos estudos relata negatividade para este vírus, mas casos positivos já foram reportados $(4,6,13,17,20)$. A pesquisa para vírus EpsteinBarr não foi realizada no caso aqui relatado.

O diagnóstico diferencial clínico do LTSCP envolve a distinção de outras formas benignas de paniculite, incluindo eritema nodoso, eritema induratum e doen- ça de Weber Christian. A biópsia revela necrose gordurosa e granulomas de células gigantes nestes tipos de paniculite lobular, mas nenhuma das lesões apresenta linfócitos atípicos $(4,10,12,18)$.

O LTSCP pode apresentar dois cursos distintos: um insidioso, apresentando nódulos subcutâneos sem sinais e sintomas sistêmicos, e outro rapidamente progressivo, associado a manifestações sistêmicas dependentes da evolução da síndrome de hemofagocitose $(15,16,18,19)$. O termo "síndrome hemofagocítica" é descrito como uma entidade caracterizada por febre, sintomas constitucionais severos, linfonodomegalia, hepatoesplenomegalia e hemofagocitose em medula óssea, baço ou linfonodos. Podem ainda estar presentes infiltrado pulmonar e erupções cutâneas, sendo a pancitopenia um achado freqüente (11). Apesar de a paciente em questão apresentar eritrofagocitose no local das lesões subcutâneas, não demonstrou dados que pudessem caracterizar uma síndrome hemofagocítica.

\section{Referências}

1. Álvarez-Larrán, A. et al. Linfoma T subcutáneo paniculítico. Med. Clin. (Barc), 3: 113-7, 1999.

2. Ashworth, J. et al. Brawny cutaneous induration and granulomatous panniculites in large cell nonHodgkin's disease. Br. J. Dermatol., 120: 563-9, 1989.

3. Au, W.Y. et al. Agressive subcutaneous panniculitis-like Tcell lymphoma: complete remission with fludarabine, mitoxantrone and dexamethasone. $\mathrm{Br}$. J. Dermatol., 143: 408-10, 2000.

4. Baselga, E. et al. Subcutaneous angiocentric T-cell lymphoma associated with fatal hemophagocitic syndrome. Int. J. Dermatol., 36: 363-7, 1997.

5. Chan, Y. et al. Subcutaneous T-cell lymphoma presenting as panniculitis in children: report of two cases. Pediatr. Pathol., 14: 595-608, 1994.

6. Cho, K.H. et al. Peripheral T-cell lymphoma involving subcutaneous tissue. Br. J. Dermatol., 132: 290-5, 1995.

7. Dargent, J.L et al. Subcutaneous panniculitis-like T-cell lymphoma: further evidence for a distinct neoplasm originating from large granular lymphocytes of T/NK phenotype. J. Cutan. Pathol., 25: 394400, 1998.

8. Gonzalez, C.L. et al. T-cell lymphoma involving subcutaneous tissue: a clinicopathologic entity commonly associated with hemophagocytic syndrome. Am. J. Surg. Pathol., 15: 17-27, 1991.
9. Hung, I.J. et al. Subcutaneous panniculitic T-cell lymphoma developing in a child with idiopathic myelofibrosis. J. Pediatr. Hematol. Oncol., 21: 38-41, 1999.

10. Kumar, S. et al. Subcutaneous panniculitic T-cell lymphoma is a tumor of cytotoxic T lymphocytes. Hum. Pathol., 29: 397-403, 1998.

11. Majluf-Cruz, A. Hemophagocytic syndrome associated with hematological neoplasias. Leuk. Res., 22: 8938, 1998.

12. Mehregan, D.A. et al. Subcutaneous T-cell lymphoma: a clinical, histopathogic, and immunohistochemical study of six cases. J. Cutan. Pathol., 21: 110-7, 1994.

13. Monterroso, V. et al. Subcutaneous tissue involvement by T-cell lymphoma. Arch. Dermatol., 132: 134550, 1996.

14. Perniciaro, C. et al. Subcutaneous T-cell lymphoma: report of two additional cases and further observations. Arch. Dermatol., 129: 1171-6, 1993.

15. Sajben, F.P. et al. Subcutaneous T-cell lymphoma: a case report and additional observations. Cutis, 58: $297-$ 302, 1996.

16. Salhany, K.E. et al. Subcutaneous panniculitis-like T-cell lymphoma: clinicopathologic, immunophenotypic, and genotypic analysis of alpha/beta and gamma/ delta subtypes. Am. J. Surg. Pathol., 22: 881-93, 1998. 
17. Von den Driesch, P. et al. Subcutaneous T-cell lymphoma. J. Am. Acad. Dermatol., 36: 285-9, 1997.

18. Wang, C.E. et al. PJ. Subcutaneous panniculitic T-cell lymphoma. Int. J. Dermatol., 35: 1-8, 1996.
19. Wasik, F. et al. Subcutaneous T-cell lymphoma: report of two cases. J. Eur. Acad. Dermatol. Venerol., 10: 62-6, 1998.

20. Yamashita, Y. et al. A case of natural killer/T cell lymphoma of the subcutis resembling subcutaneous panniculitislike T cell lymphoma. Pathol. Int., 49: 241-6, 1999. 